\title{
Das redes sociais à inovação
}

\author{
Maria Inês Tomaél \\ Doutora em ciência da informação pela Escola de Ciência da Informação \\ da UFMG e professora do Departamento de Ciência da Informação \\ da Universidade Estadual de Londrina (UEL). \\ E-mail:mitomael@uel.br
}

\section{Adriana Rosecler Alcará}

Mestranda em educação pela UEL e professora do Departamento de Ciência da Informação da UEL.

E-mail: adrianaalcara@uol.com.br

\section{Ivone Guerreiro Di Chiara}

Mestre em administração de bibliotecas pela Escola de Biblioteconomia da UFMG e professora do Departamento de Ciência da Informação da UEL.

E-mail: igchiara@conectway.com.br

\section{Resumo}

A inserção em rede é determinante para o compartilhamento da informação e do conhecimento. Isto porque as redes são espaços valorizados para o compartilhamento da informação e para a construção do conhecimento. Neste artigo, são abordadas as relações entre informação, conhecimento, aprendizagem organizacional e inovação, assim como o entorno em que as redes sociais se realizam. Essas relações constituem o foco das ligações que se estabelecem nas redes. A interação entre os atores promove $o$ compartilhamento da informação e do conhecimento, fomentando o desenvolvimento de inovações.

Palavras-chave

Redes sociais; Compartilhamento da informação e do conhecimento; Aprendizagem organizacional; Inovação.

\section{From social networks to innovation}

\section{Abstract \\ Being engaged in a network is the key element in sharing information and knowledge, since these networks are valuable spaces to attain those purposes. This article addresses the relationship among information, knowledge, organizational learning and innovation, as well as the way they are perceived and practiced. These relationships constitute the focus of the connections established in the networks. Therefore, the interaction among the actors promotes the sharing of information and knowledge, fostering the development of innovations.}

\section{Keywords}

Social networks; Information and knowledge sharing; Organizational learning; Innovation.

\section{INTRODUÇÃO}

A informação e o conhecimento estão em todas as esferas e áreas, são considerados essenciais tanto do ponto de vista acadêmico quanto profissional e, quando transformados pelas ações dos indivíduos, tornam-se competências valorizadas, gerando benefícios sociais e econômicos que estimulam o desenvolvimento e são, ainda, recursos fundamentais para formação e manutenção das redes sociais.

A configuração em rede é peculiar ao ser humano, ele se agrupa com seus semelhantes e vai estabelecendo relações de trabalho, de amizade, enfim relações de interesses que se desenvolvem e se modificam conforme a sua trajetória. Assim, o indivíduo vai delineando e expandindo sua rede conforme sua inserção na realidade social.

As redes sociais constituem uma das estratégias subjacentes utilizadas pela sociedade para o compartilhamento da informação e do conhecimento, mediante as relações entre atores que as integram.

Acreditamos que a informação e o conhecimento são passaportes essenciais para a inovação; assim, procurando estudar e aprofundar esses argumentos, este artigo apresenta uma abordagem da informação e do conhecimento como fluxos importantes das redes sociais que facilitam o processo de inovação.

\section{REDES SOCIAIS}

As pessoas estão inseridas na sociedade por meio das relações que desenvolvem durante toda sua vida, primeiro no âmbito familiar, em seguida na escola, na comunidade em que vivem e no trabalho; enfim, as relações que as pessoas desenvolvem e mantêm é que fortalecem a esfera social. A própria natureza humana nos liga a outras pessoas e estrutura a sociedade em rede.

Nas redes sociais, cada indivíduo tem sua função e identidade cultural. Sua relação com outros indivíduos vai formando um todo coeso que representa a rede. De acordo com a temática da organização da rede, é possível a formação de configurações diferenciadas e mutantes.

As redes sociais, segundo Marteleto (2001, p.72), representam "[...] um conjunto de participantes autônomos, unindo idéias e recursos em torno de valores e interesses compartilhados". A autora ressalta, ainda, que só nas últimas décadas o trabalho pessoal em redes 
de conexões passou a ser percebido como um instrumento organizacional, apesar de o envolvimento das pessoas em redes existir desde a história da humanidade.

A rede, que é uma estrutura não-linear, descentralizada, flexível, dinâmica, sem limites definidos e autoorganizável, estabelece-se por relações horizontais de cooperação. Costa et alii (2003, p. 73) atestam que a rede "é uma forma de organização caracterizada fundamentalmente pela sua horizontalidade, isto é, pelo modo de inter-relacionar os elementos sem hierarquia”.

A noção de rede remete primitivamente à noção de capturar a caça. "Por transposição, a rede é assim um instrumento de captura de informações" (FANCHINELLI; MARCON; MOINET, 2004). E esse mesmo enfoque é acentuado por Capra (2002, p.267), quando delineia a importância das redes organizacionais:

[...] na era da informação - na qual vivemos - as funções e processos sociais organizam-se cada vez mais em torno de redes. Quer se trate das grandes empresas, do mercado financeiro, dos meios de comunicação ou das novas ONGs globais, constatamos que a organização em rede tornou-se um fenômeno social importante e uma fonte crítica de poder.

Com base em seu dinamismo, as redes, dentro do ambiente organizacional, funcionam como espaços para o compartilhamento de informação e do conhecimento. Espaços que podem ser tanto presenciais quanto virtuais, em que pessoas com os mesmos objetivos trocam experiências, criando bases e gerando informações relevantes para o setor em que atuam.

A formação de redes nas organizações ocorre por meios e formas variados, desde uma conversa informal com um colega de trabalho na hora do café, em encontro com os amigos após o expediente, em reuniões, congressos, listas de discussões, portais corporativos, até situações formalmente criadas com a finalidade de alcançar resultados específicos. Krackhardt e Hanson, apud Macedo (1999), subdividiram essas redes em redes de confiança, redes de trabalho ou consulta e redes de comunicação.

As redes de confiança são aquelas que compartilham "informações politicamente delicadas" e restritas a certo número de pessoas. Já as redes de trabalho ou consulta utilizam estruturas informais e possibilitam o contato entre pessoas que possuem informações que facilitem o trabalho, ao passo que as redes de comunicação são as que possibilitam a troca de informações de trabalho com regularidade. Isto é, as chamadas “amizades de escritório”, que costumam ter um papel importante no desempenho das funções formais.

Todos os tipos apresentados estão em consonância com a afirmação de Krogh, Ichijo e Nonaka (2001, p.159), quando dizem:

As conversas nas organizações de negócios geralmente apresentam dois objetivos básicos: confirmar a existência e conteúdo do conhecimento ou criar novos conhecimentos [...] o intercâmbio de idéias, opiniões e crenças propiciado pelas conversas possibilita o primeiro e o mais importante passo para a criação do conhecimento: o compartilhamento do conhecimento tácito dentro da comunidade da rede.

Conhecimento, na visão desses autores, precisa ser transformado, desenvolvido e trabalhado dentro das organizações; caso contrário, ele será apenas um aglomerado de informações sem importância. Esse é o maior desafio da Era da Informação: criar uma organização capaz de compartilhar o conhecimento. E é nesse enfoque que as redes são mais valorizadas; ao mesmo tempo que contribuem para o aprimoramento dos ativos organizacionais, possibilitam que as organizações, distinguindo as características das redes e valendo-se delas, tornem o compartilhamento mais profícuo.

Redes sempre pressupõem agrupamentos, são fenômenos coletivos, sua dinâmica implica relacionamento de grupos, pessoas, organizações ou comunidades, denominados atores. Possibilitam diversos tipos de relações - de trabalho, de estudo, de amizade, entre outras -, apesar de quase sempre passarem despercebidas.

Redes, durante quase todo o tempo, são estruturas invisíveis, informais, tácitas. Elas perpassam os momentos da vida social, mas praticamente não se dão a ver - são o conjunto de 'conexões ocultas', como diria Capra; ou a 'estrutura submersa', nas palavras de Alberto Melucci. A noção de horizonte refere-se a essa incapacidade de se saber a extensão da rede para além de um certo ponto. Na prática social, cada uma das pessoas possui muitos círculos de relacionamento, mas não sabe quantos eles são ou como identificá-los. Na verdade, as pessoas, de modo geral, só vêem a rede quando precisam dela (COSTA et alii, 2003, p.69).

Como um espaço de interação, a rede possibilita, a cada conexão, contatos que proporcionam diferentes informações, imprevisíveis e determinadas por um interesse que naquele momento move a rede, 
contribuindo para a construção da sociedade e direcionando-a.

Castells (1999, p.498), um dos nomes mais eminentes no estudo de redes, faz uma relação direta das redes com a sociedade na Era da Informação e as define como "um conjunto de nós interconectados. Nó é o ponto no qual uma curva se entrecorta. Concretamente, o que um nó é depende do tipo de redes concretas de que falamos". Podem ser organizações de qualquer tipo, tanto formal quanto informal, tanto lícita quanto ilícita, e os nós podem também ser representados por indivíduos ou grupos de indivíduos.

O contexto em que estamos inseridos desencadeia uma série de mudanças na rotina dos indivíduos, e uma delas evidencia as redes como ponto de convergência da informação e do conhecimento. Para Sodré (2002, p.14), rede é "onde as conexões e as interseções tomam o lugar do que seria antes pura linearidade". Essas conexões e interações no âmbito das redes sociais ocorrem pelo contato direto (face a face) e pelo contato indireto utilizando-se um veículo mediador, como a Internet, o telefone, ou outro meio. Enfim, podemos dizer que redes sociais envolvem um conjunto de atores que mantêm ligações entre si.

A partir do desenvolvimento dos meios de comunicação, principalmente depois da Internet, as relações sociais prescindem do espaço físico e do geográfico, elas ocorrem independentes do tempo e/ou do espaço. E, mesmo assim, as relações em uma rede refletem a realidade ao seu redor e a influência. Devido a essa dimensão, Wellman (1996) verifica, na rede, sua identidade singular em determinada situação, isto é, a representação e a interpretação das relações em rede estão fortemente ligadas à realidade que a cerca; a rede é influenciada pelo seu contexto e esse por ela.

A interação constante ocasiona mudanças estruturais e, em relação às interações em que a troca é a informação, a mudança estrutural que pode ser percebida é a do conhecimento, quanto mais informação trocamos com o ambiente que nos cerca, com os atores da nossa rede, maior será nossa bagagem de conhecimento, maior será nosso estoque de informação, e é nesse poliedro de significados que inserimos as redes sociais.

O professor Stanley Milgram, da Universidade de Havard, nos Estados Unidos, em 1967, defendeu a tese segundo a qual estamos distantes de qualquer outra pessoa do mundo, a seis graus, isto é, seis pessoas nos separam de qualquer outra pessoa. Essa tese ficou conhecida como "mundo pequeno" e "teoria dos seis degraus". Para chegar a esse número, o professor enviou cartas a 160 moradores de Boston e Omaha (Nebraska-EUA), escolhidas aleatoriamente, instruindo-as para que reenviassem a carta recebida a uma pessoa-alvo - um morador de Sharon, Massachussets, que trabalhava em Boston -, por meio de contatos que já tinham, amigos, conhecidos que pudessem ajudar na entrega da carta, cada pessoa pela qual a carta passasse deveria escrever seu nome no envelope, assim foi possível monitorar seu percurso. Milgram identificou que o número médio de intermediários, do primeiro contato até a pessoa alvo, foi de seis pessoas (COSTA et alii, 2003; MOLINA, 2004).

Tendo como base essa experiência, pesquisadores da Columbia University (DODDS; MUHAMAD; WATTS, 2003) realizaram uma pesquisa com mais de $60 \mathrm{mil}$ usuários de e-mail, procurando atingir 18 pessoas-alvo em 13 países, por meio do encaminhamento de mensagens para conhecidos. A pesquisa obteve grande êxito. Os pesquisadores acreditam que isso se deve primeiramente aos intermediários, que, por meio de seus contatos, fizeram com que as mensagens chegassem às pessoas-alvo. Pelos resultados, os pesquisadores constataram que as mensagens alcançaram seus destinatários por meio de um número médio de cinco a sete etapas, apesar de, em alguns casos, a diferença ter sido substancial. Assim concluíram que o sucesso das redes sociais globais depende dos esforços individuais.

As duas pesquisas demonstram que a rede social constitui importante recurso profissional e pessoal. Estar em contato com pessoas que conheçam uma pessoa-alvo em razão de um interesse específico -, ou alguém que a conheça, já é um passo além para a conquista de um objetivo.

As redes sociais ultrapassaram o âmbito acadêmico/ científico, conquistando e ganhando espaço em outras esferas. E podemos observar esse movimento chegando à Internet e conquistando cada vez mais adeptos, aglutinando pessoas com objetivos específicos, ou apenas pelo prazer de trazer à tona ou desenvolver uma rede de relacionamentos*. Isso é possibilitado por um software social que, com uma interface amigável, integra recursos além dos da tecnologia da informação. $\mathrm{O}$ uso desses recursos gera uma rede em que os membros convidam seus amigos, conhecidos, sócios, clientes, fornecedores e outras pessoas de seus contatos para participar de sua rede, desenvolvendo uma rede de contatos profissional e pessoal, que certamente terá pontos de contatos com

\footnotetext{
* http://www.ecademy.com; http://www.econozco.com; http://www. linkedin.com; http://www.orkut.com; http://www.everyonesconnected. com; http://www.ryze.com.
} 
outras redes. Enfim, são ambientes que possibilitam a formação de grupos de interesses que interagem por meio de relacionamentos comuns.

A idéia de redes nas ciências sociais é aplicada à sociedade como um conjunto de relações e funções desempenhado pelas pessoas umas em relação às outras. "Como característica das sociedades complexas, cada associação de seres humanos funciona de maneira muito específica, o que cria uma dependência funcional entre os indivíduos". Os vínculos entre estes indivíduos se fazem ininterruptamente, são ligações invisíveis, porém reais (MARTELETO, 2000, p.78).

\section{INFORMAÇÃO E CONHECIMENTO}

$\mathrm{O}$ espaço em que as redes sociais se constituem e se proliferam são inerentes à informação e ao conhecimento, uma vez que são eles que movimentam as redes.

A importância da informação no desempenho das empresas é destacada por diversos autores, entre os quais Lesca e Almeida (1994, p.67) quando afirmam que "a informação é um vetor estratégico importantíssimo, pois pode multiplicar a sinergia dos esforços ou anular o resultado do conjunto dos esforços". Drucker (1992) acrescenta ainda que ela é fator de produção importante para a obtenção de vantagem competitiva, uma vez que os fatores tradicionais - terras, mão-de-obra e recursos financeiros - por si sós já não garantem a competitividade.

A literatura (McGARRY, 1999; DAVENPORT; PRUSAK, 1998) reconhece a dificuldade em conceituar informação e conhecimento, destacando que a epistemologia concentra esforços na tentativa de estabelecer o significado de informar e conhecer.

Assim, entendemos que a informação está no domínio pessoal do receptor, isto é, é ele quem define se a mensagem recebida acrescenta algum valor ao estado anterior, estabelecendo sentido e modificando atitudes.

Informação é sempre fluxo e para o sujeito ela funciona como troca com o mundo exterior, o que lhe confere seu caráter social. Assimilada, interiorizada e processada por um sujeito específico, ela é a base para sua integração no mundo, propiciando ajustes contínuos entre o mundo interior e o mundo exterior (TÁlAMO, 2004, p.1).

Ao considerar a importância das pessoas nos processos informacionais, Choo (1998) ressalta que as organizações utilizam a informação por formas distintas. Na primeira delas, a informação é coletada do ambiente e interpretada para a construção de significados (sense making), procurando sua retenção. $\mathrm{Na}$ outra forma, cria novos conhecimentos (knowledge creating) por meio de sua conversão (tácito para explícito) e do compartilhamento da informação, procurando a inovação. Por último, procura e analisa informações para a tomada de decisões (decison making).

A relação entre informação e conhecimento é representada por Choo (1998) por um ciclo, no qual atrela a necessidade, a busca e o uso de informação, levando de uma situação a outra. Essas etapas compõem a estrutura cognitiva interna dos indivíduos e sua organização emocional. Para o autor, esse modelo pode ser analisado usando-se como parâmetro os seguintes aspectos:

- necessidade de informação: contém elementos cognitivos, afetivos e situacionais. É primeiramente sentida como uma incerteza. Conforme esse sentimento vai diminuindo, a necessidade de informação progressivamente vai chegando à consciência e então a questão é formalizada;

- busca pela informação: o modelo é analisado valendose das seguintes categorias*: iniciação, encadeamento, pesquisa, diferenciação, monitoramento, extração, verificação e conclusão. As três primeiras categorias são importantes para o desenvolvimento do foco e estratégia da pesquisa, as demais são fortemente influenciadas pelo ambiente cultural e organizacional, ou seja, a escolha das fontes de informação depende da inserção do indivíduo e da motivação que gerou a busca;

- uso da informação: seleção e processamento de informação resultando em um novo conhecimento ou ação. Nesse aspecto a informação é freqüentemente usada para responder a questões, resolver problemas, tomar decisões, negociar posições, ou construir significados para determinada situação. As pessoas sentem satisfação e confiança quando suas pesquisas têm bons resultados, mas, quando ocorre o contrário, sentem desapontamento e frustração.

Estabelecendo uma relação similar entre informação e conhecimento, Barreto (1996) ressalta "se a informação é percebida e aceita como tal, colocando o indivíduo em um estágio melhor, consciente consigo mesmo e dentro do mundo onde se realiza a sua odisséia individual”, então essa relação de fato se realizou.

Essa relação é abordada por Nonaka e Takeuchi (1997, p.64) quando afirmam: "a informação é um fluxo de mensagens, enquanto o conhecimento é criado por esse

* Essas categorias são empregadas por Choo com base na literatura. 
próprio fluxo de informação, ancorado nas crenças e compromissos de seu detentor".

Desse modo, o processo de conhecimento consolida-se a partir de informações com valor agregado, assimiladas pelos indivíduos ou pelas organizações, incorporadas às experiências e saberes anteriores, conduzindo à ação.

O fluxo da informação para o conhecimento também é abordado por Davenport e Prusak (1998, p.7), que criaram os quatro Cs, de forma similar aos quatro Ps de marketing, em que apresentam um processo da transformação da informação em conhecimento. As pessoas precisam encarregar-se dessa tarefa, e, conforme sugerem os autores, é preciso estabelecer:

Comparação - de que forma as informações relativas a essa situação se comparam com outras situações conhecidas? Conseqüências - que implicações essas informações trazem para as decisões e tomadas de ação? Conexões - quais as relações desse novo conhecimento com o conhecimento já acumulado? Conversação - o que as outras pensam dessa informação?

O conhecimento é inerente às pessoas. Conseqüentemente, o agenciamento dos relacionamentos e a confiança entre os indivíduos nas organizações têm papel determinante na criação do conhecimento, isto porque, ressalta Krogh, Ichijo e Nonaka (2001, p.61): "Para compartilhar o conhecimento pessoal, os indivíduos devem confiar em que os outros estejam dispostos a ouvir e a reagir às suas idéias". Os bons relacionamentos possibilitam condições para o compartilhamento de insights e para a livre discussão das preocupações, permitindo a organização espontânea de pequenas comunidades, "fonte de criação do conhecimento nas empresas".

Miranda (1999, p.287) diferenciou os tipos de conhecimento, classificando-os em explícito, tácito e estratégico:

conhecimento explícito é o conjunto de informações já elicitadas em algum suporte (livros, documento etc.) e que caracteriza o saber disponível sobre o tema específico; conhecimento tácito é o acúmulo de saber prático sobre um determinado assunto, que agrega convicções, crenças, sentimentos, emoções e outros fatores ligados à experiência e à personalidade de quem o detém; conhecimento estratégico é a combinação de conhecimento explícito e tácito formado a partir das informações estratégicas e de informações de acompanhamento, agregando-se o conhecimento de especialistas (grifo nosso).
Ainda com relação aos tipos de conhecimento, destacamos Nonaka e Takeuchi (1997, p. 13), que também classificam o conhecimento em tácito e explícito. O conhecimento explícito é facilmente transmitido entre os indivíduos, pois "[...] pode ser articulado na linguagem formal, inclusive em afirmações gramaticais, expressões matemáticas, especificações, manuais e assim por diante". O conhecimento tácito, por sua vez, é o conhecimento pessoal incorporado à experiência individual e envolve fatores intangíveis (crenças pessoais, valores e perspectivas) e é difícil ser articulado na linguagem formal.

É importante lembrar que esses dois tipos de conhecimentos são inerentes às redes sociais. E é a interação entre o conhecimento tácito e explicito que permitirá a criação de novos conhecimentos. Nonaka e Takeuchi (1997, p. 67) afirmam que "o modelo dinâmico da criação do conhecimento humano é criado e expandido através da interação social entre o conhecimento tácito e o conhecimento explícito". Eles denominam essa interação de "conversão do conhecimento", chamando a atenção para a importância de visualizar essa conversão como um "processo 'social' entre indivíduos e não confinada dentro de um indivíduo". Assim são as redes sociais, elas se mantêm valendo-se da interação entre diversos indivíduos para a criação de novos conhecimentos.

\section{COMPARTILHAMENTO DA INFORMAÇÃO E DO CONHECIMENTO}

Reconhecendo-se como certo que a informação e o conhecimento são inerentes às redes sociais, sua importância social e econômica é conseqüência do efeito que causam nas pessoas e nas organizações. Nesse âmbito, constatamos a necessidade de compartilhá-los para que possam trazer mudanças no contexto em que estão inseridos.

Para Dixon (2000), o termo compartilhar tem dois significados: dar uma parte, o que requer generosidade, $\mathrm{e}$ ter em comum um sistema de crenças compartilhado. Para a autora, o termo compartilhar que nós usamos freqüentemente, quando falamos do intercâmbio de conhecimento, pode aparentar uma escolha de palavras um tanto estranha, pois usualmente são utilizados termos como capturar, disseminar ou transferir. Mas a palavra certa nesse contexto é realmente compartilhar, que implica a idéia de dividir alguma coisa que possuímos. Em português, a palavra é sinônimo de compartir, que significa dividir e distribuir, e é uma palavra com uma 
conotação forte, pois exige mais doação dos indivíduos do que disseminar, transferir ou capturar.

De acordo com a referida autora, a idéia de compartilhar conhecimento é baseada em três mitos:

O primeiro deles é que basta às empresas construir bases de dados sofisticadas, que o conhecimento virá. As empresas adotam uma estrutura com bases de dados eletrônicas, enfim um estoque de conhecimento que se constitui em apenas armazenamento do conhecimento e da informação, quando o desafio é o uso desses recursos.

O segundo mito é que a tecnologia, considerada imprescindível para o processo de compartilhamento da informação e do conhecimento, pode substituir o contato pessoal. A reunião de pessoas em um só espaço físico tem um alto custo (passagens, estadas, entre outras despesas), mas traz grandes resultados em termos de compartilhamento da informação e do conhecimento. O que ocorre na prática é que é necessário o uso da tecnologia combinado com o contato pessoal para a transferência ou compartilhamento do conhecimento e da informação.

E o terceiro mito é baseado na crença de que a troca de conhecimento ocorre somente em organizações nãocompetitivas ou com cultura para a colaboração e que, portanto, primeiro é preciso criar uma cultura de aprendizagem. Se as pessoas começam a compartilhar idéias e conseguem perceber a importância desse processo, o próprio compartilhamento cria a cultura da aprendizagem.

A definição de redes sociais apresentada por Marteleto (2001) contempla a idéia de compartilhamento de valores e interesses que, para promover o fortalecimento da rede, dependem do compartilhamento da informação e do conhecimento.

Reportando-se às redes de trabalho nas organizações, Yu, Yan e Cheng (2001) também ressaltam os benefícios da cooperação e compartilhamento da informação, quando afirmam que a globalização dos negócios foi acelerada nas últimas duas décadas devido ao rápido desenvolvimento da tecnologia de produção e informação, aumentando a pressão dos custos e ocasionando demanda mais agressiva dos clientes. Os esquemas de produção e distribuição foram modificados, e novos padrões de relacionamento entre fornecedores, produtores, varejistas e outras partes foram introduzidos no mercado, notadamente sob o esquema de redes.

De acordo com Hanfield e Nichols, apud Shore e Venkatachalan (2004), dois parâmetros são essenciais para integração e coordenação da rede: colaboração e tecnologia. Para esses autores, o trabalho em rede requer cuidadosa coordenação e integração. A colaboração, vista por eles como um processo social, é necessária para compartilhar a informação e, por conseqüência, o conhecimento, para integrar horizontalmente as operações da rede. Já o compartilhamento é visto mais como um processo tecnológico. A integração, necessária para administrar a rede, requer tanto colaboração quanto compartilhamento da informação.

A importância da tecnologia no processo de compartilhamento da informação e do conhecimento também é reconhecida por Davenport e Prusak (1998, p.117), quando, referindo-se à transferência de conhecimento, afirmam que esse processo não poderia ocorrer "[...] sem as ferramentas propiciadas pela tecnologia da informação [...]". Os autores chamam a atenção para a relevância dos valores, normas e comportamentos que constituem a cultura da empresa que são determinantes para o grau de sucesso da transferência do conhecimento.

A importância das pessoas no compartilhamento da informação e do conhecimento é salientada por Davenport (1994) em outro trabalho, quando diz que:

- as organizações devem começar a pensar como as pessoas usam a informação, e não como usam os recursos tecnológicos;

- as informações que as pessoas consideram importantes nas organizações, em grande parte, não são passíveis de serem gerenciadas por recursos tecnológicos;

- as pessoas agregam valor aos dados interpretando-os e contextualizando-os, por isso os gerentes preferem obter informações das pessoas;

- as pessoas são ativos importantes e determinantes no contexto informacional, assim qualquer modelo ou mapa informacional deve incluí-las;

- a comunicação eletrônica só é possível se primeiro houver a comunicação face a face.

Coerente com essas afirmações, Dixon (2000) adverte que a tecnologia não substitui o contato pessoal.

É claro que a tecnologia faz com que o compartilhamento da informação e do conhecimento seja mais fácil, mas, apesar das ferramentas colocadas à disposição das pessoas para facilitar esse processo, Davenport e Prusak (1998) ressaltam algumas barreiras para a transferência do conhecimento nas organizações. Dentre elas, algumas 
podem ocorrer também nas redes sociais, como é o caso da falta de confiança mútua, diferentes culturas, vocabulários e quadros de referência distintos. Mas são barreiras passíveis de serem facilmente superadas, conforme propõem os autores, o são pelas próprias características das redes sociais.

Para que a transferência e conseqüente compartilhamento da informação e do conhecimento obtenham sucesso, esses autores destacam alguns aspectos:

- linguagem comum, sem a qual as pessoas não se entenderão e tampouco confiarão umas nas outras;

- necessidade, às vezes, do contato face a face;

- A cultura comum é ressaltada como um aspecto importante para melhor transferência do conhecimento, pois, segundo eles, "quanto mais próximas as pessoas estão da cultura do conhecimento que está sendo transferido, mais fácil é o compartilhamento e a troca" (DAVENPORT; PRUSAK, 1998, p.121).

- o status do possuidor do conhecimento, que inspira ou não confiança no conhecimento e na informação compartilhada.

No entanto, no caso das redes sociais, esses aspectos estão presentes no seu desenvolvimento. Caso contrário, elas já estariam fragilizadas ou nem existiriam. Prevalece uma linguagem e uma cultura comuns, oriundas dos próprios interesses, o contato independe da interação pessoal, e, quanto ao status do possuidor do conhecimento, ele já é reconhecido a partir do momento em que esse passa a ser integrante da rede.

Portanto, entre as estratégias a que as redes sociais podem recorrer para se fortalecerem, está o compartilhamento da informação e do conhecimento.

Porém, se conhecimento e informação, conforme salienta Figueiredo (2002), representam poder, reportando-se ao primeiro conceito, por que alguém compartilharia o que sabe?

Tonet (2004, p.1) responde a essa questão, quando afirma:

A realidade vem mostrando às organizações a necessidade de criar e reter o conhecimento [...] para o cumprimento dos propósitos organizacionais; e também, necessidade de estimular colaboradores e parceiros a compartilharem o conhecimento que possuem e que as organizações precisam para apresentar bom desempenho organizacional.

Ci. Inf., Brasília, v. 34, n. 2, p. 93-104, maio/ago. 2005
Além disso, conforme destaca Dixon (2000), as pessoas gostam de dividir o que sabem, tanto é assim, que, quando sabemos alguma coisa, sempre pensamos na utilidade do conhecimento para outras pessoas.

Mas o compartilhamento da informação e do conhecimento só terá resultados se implicar um processo de aprendizagem, pois o simples acesso sem esse processo não modifica a realidade, perde, portanto, o sentido. Assim, é preciso lembrar da afirmativa de Dixon (2000), quando ela diz que, se as pessoas começam a compartilhar idéias e conseguem perceber a importância desse processo, o próprio compartilhamento cria a cultura da aprendizagem.

\section{INOVAÇÃO E APRENDIZAGEM ORGANIZA- CIONAL}

A busca constante pela inovação, por meio da criação e desenvolvimento de novos produtos e processos, diversificação, qualidade e absorção de tecnologias avançadas, é indispensável para assegurar elevados níveis de eficiência, produtividade e competitividade das organizações. Isso implica acumulação constante de conhecimentos e capacitação tecnológica contínua. Nesse contexto, insere-se a aprendizagem organizacional (aprendizado contínuo e interativo), configurando-se como o processo mais importante para o desenvolvimento da inovação tecnológica.

A aprendizagem organizacional, segundo Fleury e Fleury (1995, p.19), "é um processo de mudança, resultante de prática ou experiência anterior, que pode vir ou não a manifestar-se em uma mudança perceptível de comportamento".

aprendizado em uma organização significa entender, compreender e aprender com o passado e discuti-lo, com a finalidade de orientar as ações futuras. A idéia é difundir um conjunto de iniciativas, de técnicas e de formas novas de comunicação que permita à organização, ao entender o passado, antecipar o futuro. É importante salientarmos que esse é um processo que deve ser construído a longo prazo.

A aprendizagem organizacional tem como objetivo principal resultar em inovação, na qual as pessoas aprimoram continuamente suas capacidades, trabalhando juntas na investigação ou em assuntos de maior complexidade, visando a conscientizar-se para profundas modificações pessoais, em que possam questionar constantemente seus modelos mentais e criar ambientes seguros para que outras pessoas façam o mesmo, 
As organizações que cultivam a aprendizagem organizacional são também denominadas organizações que aprendem ou organizações de aprendizagem, que, segundo Garvin (1993), são organizações com habilidades para criar, adquirir, transferir conhecimentos e modificar comportamentos, refletindo o novo conhecimento e o novo insight. Segundo o autor, as organizações de aprendizagem possuem habilidades em cinco principais atividades: resolução sistemática de problemas, experimentação de novas abordagens, aprendizado com base na própria experiência e história passada, aprendizado por meio de experiências e melhores práticas de outros e a transferência do conhecimento de forma rápida e eficiente por toda a organização.

As organizações de aprendizagem são para Esteves (2002, p.10) "organizações que têm dentro de si o embrião da aprendizagem e da inovação". A organização que aprende é aquela que aprende em conjunto, que lapida e extrai o que o indivíduo tem de melhor, para ser compartilhado e comunicado entre os demais indivíduos do grupo, concorrendo para que a organização se torne reflexiva e indagadora.

Para Senge (1995b, p.334), este tipo de organização que aprende tem algumas características diferenciais em suas equipes de trabalho.

Para uma equipe que pratique esta disciplina, é útil ter uma razão para falar e aprender uma situação que obrigue a deliberação, uma necessidade de solucionar um problema, o desejo coletivo de criar algo novo, ou um impulso para promover novos relacionamentos com outras partes da organização. Esta primeira preocupação torna-se-á o 'campo da prática' preliminar para o desenvolvimento da equipe. À medida que adquirir confiança, a equipe avança para considerar outras questões.

Além do engajamento das pessoas com o fim de solucionar problemas, do desejo coletivo de criar algo novo e do impulso para promover novos relacionamentos com outras partes da organização, é necessário incorporar na organização as cinco disciplinas de Senge.

Essas disciplinas, a que se refere Senge (1995a, p.17), são um conjunto de práticas de aprendizagem por meio das quais as pessoas se modificam, adquirindo novas habilidades, conhecimentos, experiências e níveis de consciência. São explicitadas, a seguir, as cinco disciplinas:

a) raciocínio sistêmico: criar uma forma de analisar e uma linguagem para descrever e compreender as forças e interrelações que moldem o comportamento dos sistemas; b) domínio pessoal - autoconhecimento: expandir a capacidade pessoal para criar os resultados que se desejam e, conseqüentemente, a consciência do que as pessoas querem objetivando seus esforços;

c) modelos mentais: refletir, esclarecer continuamente e melhorar a imagem que cada um tem do mundo, a fim de verificar como moldar atos e decisões;

d) objetivo comum: ter a capacidade de transmitir aos outros a imagem do futuro que se pretende criar. Transformar um objetivo individual em um objetivo comum;

e) aprendizagem em equipe: elaborar uma lógica comum, para que possam confiavelmente desenvolver inteligência e capacidade de forma que o resultado das habilidades grupais seja maior e mais significativo que a somatória dos talentos individuais.

As organizações orientadas para o aprendizado, para Balceiro (2004, p.5), também adotam algumas práticas diferenciadas como:

Cultivar uma visão integral das coisas que as fazem funcionar, daquilo que faz uma determinada mudança fixar-se e de como diagnosticar necessidades e projetar novas ações para um aprendizado eficaz. Além disso, estas organizações estão constantemente preocupadas em realizar programas de treinamento, capacitação e aperfeiçoamento de seus funcionários, a fim de aumentar a sua capacidade de mudar.

Uma organização voltada para o aprendizado não se constrói em curto prazo, por isso devemos conduzi-la cuidadosamente para mentalidade que favoreça ambiente de contínuo desenvolvimento e compromisso com o aprendizado.

O conhecimento e o aprendizado interativos são elementos que formam a base fundamental, configurando-se como a melhor forma para indivíduos, empresas, regiões e países se adaptarem às intensas mudanças no mercado, bem como intensificarem a geração de inovações.

Lastres e Ferraz (1999) ressaltam que é necessária uma "simbiose" entre os processos de aprendizagem e de conhecimento, pois o aprendizado possibilita a acumulação de conhecimentos, os quais irão sustentar teoricamente os avanços científicos, técnicos e organizacionais que resultarão em inovações.

A aprendizagem organizacional impulsiona a inovação. Lemos (1999) enfatiza que o processo de inovação é um 
processo de aprendizado interativo, requerendo intensas relações entre diferentes agentes. Essas relações, que são configuradas como redes, devem ocorrer com os agentes internos da organização (indivíduos que atuam nos diferentes setores) e, especialmente, com os agentes externos, tais como instituições de pesquisas e universidades, agências governamentais de fomento e financiamento, associações empresariais, organizações não-governamentais, entre outras. A capacidade de as organizações se inserirem nessas redes e nesse novo contexto está totalmente atrelada ao investimento da capacitação dos indivíduos, que são os responsáveis pela geração de conhecimentos e inovações.

Barbieri (1997) evidencia que, dependendo da área de estudo, o termo inovação apresenta diferentes significados. Na área mercadológica, a inovação é considerada qualquer modificação percebida pelo usuário, mesmo não ocorrendo alteração física do produto. $\mathrm{Na}$ área produtiva, a inovação é a introdução de novidades materializadas em produtos, processos e serviços, novos ou modificados. Outros enfoques relacionam a inovação a idéias de alto risco, proporcionando elevados benefícios à organização, que a desenvolve, ou processos que produzem fortes impactos econômicos à sociedade.

Lemos (1999), seguindo a abordagem neoschumpeteriana, salienta que os avanços resultantes de processos inovativos são fatores básicos na formação de padrões de transformação da economia, bem como de seu desenvolvimento de longo prazo.

É importante destacarmos que a teoria de Joseph Schumpeter configura-se como marco fundamental da discussão sobre a natureza e as características da inovação. Schumpeter enfocou a importância das inovações e dos avanços tecnológicos no desenvolvimento das empresas e da economia. Ele ressaltou que a inovação promove o ciclo econômico (desenvolvimento econômico) e os elementos crédito, capital, juro e lucro fazem parte desse processo (ALMEIDA, 1995; LEMOS, 1999).

A inovação tecnológica significa a introdução de produtos, processos e serviços baseada em novas tecnologias. Sáenz e García Capote (2002, p.69) ressaltam que o "processo de inovação é a integração de conhecimentos novos e de outros existentes para criar produtos, processos, sistemas ou serviços novos ou melhorados". E a inovação tecnológica "é a primeira utilização - incluindo a comercialização nos casos em que se aplica - de produtos, processos, sistemas ou serviços, novos ou melhorados".
Ainda com relação ao conceito de inovação tecnológica, Barbieri (1997) a entende como um processo desenvolvido por uma organização que visa a introduzir no mercado produtos e processos incorporadores de novas soluções técnicas, funcionais ou estéticas. Se essas soluções são completamente novas, ou seja, se ainda não foram disseminadas por outras organizações, esse tipo de inovação pode ser considerado como inovação pioneira (novidades absolutas). Ao passo que, se essas soluções já foram utilizadas por outras organizações, a inovação é considerada relativa (novidades relativas).

A inovação tecnológica é um processo complexo que envolve várias fases, desde a idéia inicial, originada a partir de um problema ou uma oportunidade de negócio, até o desenvolvimento do produto ou processo e seu lançamento no mercado.

Referindo-se às noções lineares sobre o processo inovativo, Lemos (1999) ressalta que hoje a ciência não pode mais ser considerada a fonte absoluta de inovação, bem como o mercado também não deve ser apontado como o único elemento determinante para que ela ocorra. Os diferentes aspectos da inovação a tornaram um processo complexo, interativo e não-linear. A interação é elemento fundamental para a inovação. A autora afirma que a organização não inova sozinha. Ela precisa de fontes de informações e conhecimentos que podem estar dentro ou fora da organização. Por isso, a inovação é um processo interativo que ocorre com a contribuição de vários agentes (econômicos e sociais). E essa interação pode acontecer entre os diferentes departamentos da própria organização ou com outras organizações externas, como, por exemplo, universidades e instituições de pesquisas.

Assim funcionam as redes sociais. Elas dependem da interação de diversos atores - internos e externos à organização - dispostos a compartilhar informações e experiências, visando ao aprendizado organizacional e, conseqüentemente, contribuindo para a construção de novos conhecimentos.

Como complemento à idéia de Lemos (1999), Sáenz e García Capote (2002) salientam que a inovação deve partir de uma combinação das necessidades sociais e das demandas do mercado com os meios científicos e tecnológicos. Apesar de evidenciar o âmbito de pesquisa e desenvolvimento como imprescindível para impulsionar as inovações, os autores não o consideram exclusivo. Ressaltam a importância de incluir ao processo inovativo atividades científicas, tecnológicas, produtivas, financeiras e comerciais. 
Além disso, os processos inovativos devem contemplar o trabalho com " $[. .$.$] redes formais e informais como o$ fator mais relevante para transferir conhecimento entre todos os participantes". Essa nova dinâmica de processo de inovação produz resultados a curto e longo prazos, bem como "[...] induzem padrões de inovação e difusão, incluindo a criação de novos grupos interdisciplinares" (SÁENZ; GARCÍA CAPOTE, 2002, p.84).

Analisando-se a inovação de uma forma sistêmica, é importante enfatizar a transferência e difusão de idéias, habilidades, conhecimentos e informações. "Os canais e as redes através dos quais essas informações circulam estão inseridos em um contexto social, político e cultural. Eles são fortemente guiados e restringidos pela estrutura institucional" (MANUAL DE OSLO, 2004, p.35).

De acordo com o Manual de Oslo (2004), vários fatores humanos, sociais e culturais são identificados como cruciais para que o processo de inovação ocorra eficazmente dentro das organizações. Esses fatores influenciam diretamente no aprendizado organizacional e referem-se à facilidade de comunicação interna, às interações informais, à cooperação e aos canais de transmissão de informações e habilidades entre as organizações e dentro de cada uma individualmente. Portanto, a capacidade inovadora de uma organização depende de seu aprendizado, isso é, da difusão do conhecimento a uma larga gama de indivíduos dentro da organização.

Ressaltando a importância das redes no contexto atual das organizações, Lemos (1999, p.135) afirma que a formação de redes é o "formato organizacional mais adequado para promover o aprendizado intensivo para a geração de conhecimento e inovações".

Nesse sentido, Van Aken e Weggeman (2000) destacam que as redes são mecanismos imprescindíveis para otimizar os recursos organizacionais, para aumentar a capacidade tecnológica na geração de inovações e para a absorção de know-how. Complementando essa idéia, Austin, apud Schlemm e Souza (2004), afirma que a constituição de redes, em seus diferentes níveis e aplicações, flexibiliza as relações entre as pessoas, potencializando o compartilhamento de informação entre as organizações e os indivíduos e, conseqüentemente, contribuindo para a geração de conhecimento e inovação tecnológica.

\section{REFLEXÕES FINAIS}

As redes sociais influenciam tanto a difusão de inovações quanto a propagação da informação e do conhecimento que oportuniza o desenvolvimento de inovações. A literatura nos permite inferir que as redes sociais são recursos importantes para a inovação, em virtude de manterem canais e fluxos de informação em que a confiança e o respeito entre atores os aproximam e os levam ao compartilhamento de informações que incide no conhecimento detido por eles, modificando-o ou ampliando-o.

As interações, que movimentam as redes, são representadas por relações sociais, econômicas, de trabalho, etc., que, essencialmente, possibilitam o compartilhamento de informação e de conhecimento. Dependendo dos interesses que movimentam as interações na rede, esta pode ser seccionada em grupos que geralmente são profícuos para a própria rede, isto por mobilizarem atores que estejam envolvidos com uma temática específica. Favorecem, igualmente, ligações entre atores com o poder de direcionar os fluxos de informação a indivíduos que partilham de interesses comuns, proporcionando maiores condições para a inovação.

O direcionamento dos fluxos de informação pode fortalecer e delinear uma rede, propiciando sinergia às funções nela desdobradas. A informação, ferramenta estratégica essencial nas organizações, mobiliza as redes e as torna um vetor estratégico importante e contumaz.

A necessidade de informação é imanente ao indivíduo e às organizações. O caminho natural para buscá-la é o das redes, especialmente por meio dos nossos pares com quem mais compartilhamos. Mediante o uso da informação, o estado existente modifica-se, expandindo o conhecimento que vai fortalecer o fluxo da informação e respaldar os processos individuais e coletivos.

Para que seja mais eficiente, o compartilhamento da informação e do conhecimento em rede requer a adoção de uma postura de cooperação, em que os atores utilizem múltiplos recursos, valorizando tanto o contato pessoal quanto o uso da tecnologia como ferramenta de comunicação que culmine no aprendizado.

A aprendizagem é promovida pelo compartilhamento e o uso da informação, os quais, como resultado, possibilitam novos aportes, entre eles os mais significativos são os novos conhecimentos e as novas habilidades. As redes que constituem espaços em que o compartilhamento da informação e do conhecimento é proficiente e natural são espaços também de aprendizagem e, assim, tornam-se um ambiente para o desenvolvimento e para a inovação. 
As interações entre pessoas, entre organizações e entre os elementos humanos sociais e culturais interferem diretamente nos processos inovativos, e são essas interações que permitem e acirram a aprendizagem organizacional, fortalecendo as relações e os benefícios advindos delas.

As organizações são formadas por pessoas que, por sua vez, são pontos (nós) das redes sociais e detentoras do conhecimento e das habilidades. Quando compartilhados (conhecimento e habilidades) transformam-se em aprendizagem organizacional, que resulta na acumulação de novos conhecimentos e, conseqüentemente, impulsiona as inovações.

As ligações na rede acentuam a capacidade de inovação individual e organizacional, capacidade esta que reflete no sistema de inovação em que os atores estão inseridos, promovendo o desenvolvimento local, que incide na expansão econômica e social de uma nação.

Artigo recebido em 03/10/2005 e aceito para publicação em 05/01/2006.

\section{AGRADECIMENTOS}

Gostaríamos de agradecer a colaboração de Elaine Cristina Liviero Tanzawa, Valéria Cristina Heckler Piedade e dos alunos de iniciação científica Jéssica Luis Barreto e Jorge Luis Rodrigues.

\section{REFERÊNCIAS}

ALMEIDA, Eduardo Simões de. Considerações teóricas sobre o sistema schumpeteriano. Economia $\mathcal{E}$ Empresa, São Paulo, v. 2, n. 2, p. 4-12, abr.jun. 1995.

BALCEIRO, Raquel Borba. A aprendizagem organizacional e a inovação: o caso Pfizer. Disponível em: <http://crie.coppe.ufrj.br/home/artigos/ artigos.pdf $>$. Acesso em: 24 abr. 2004.

BARBIERI, José Carlos. A contribuição da área produtiva no processo de inovações tecnológicas. Revista de Administração de Empresas, São Paulo, v. 37, n. 1, p. 66-77, jan./mar. 1997.

BARRETO, Aldo de Albuquerque. A eficiência técnica e econômica e a viabilidade de produtos e serviços de informação. Ciência da Informação, Brasília, v. 25, n. 3, p. 405-414, 1996.

CAPRA, Fritjof. As conexões ocultas: ciência para uma vida sustentável. São Paulo: Cultrix, 2002.

CASTELLS, Manuel. A sociedade em rede. 2. ed. São Paulo: Paz e Terra, 1999.

CHOO, Chun Wei. The knowing organization: how organizations use information to construct meaning, create knowledge, and make decisions. New York: Oxford Univerty, 1998.

COSTA, Larissa et al. (Coord.). Redes: uma introdução às dinâmicas da conectividade e da auto-organização. Brasília: WWF-Brasil, 2003.
DAVENPORT, Thomas H. Saving it's soul: human-centered information management. Harvard Business Review, v. 72, n. 2, p. 119 131, Mar./Apr. 1994.

DAVENPORT, Thomas H.; PRUSAK, Laurence. Conhecimento empresarial: como as organizações gerenciam o seu capital intelectual. 6. ed. Rio de Janeiro: Campus, 1998.

DIXON, Nancy. Common knowledge: how companies thrive by sharing what they know. Harvard: Harvard Business School Press, 2000.

DODDS, Peter Sheridan; MUHAMAD, Roby; WATTS, Duncan J. An experimental study of search in global social networks. Science, Washington, v. 301, p. 827-829, Aug. 2003.

DRUCKER, Peter F. Administrando para o futuro: os anos 90 e a virada do século. São Paulo: Pioneira, 1992.

ESTEVES, George André Galvão. Administração, modelos organizacionais e a aprendizagem continuada como fato gerenciador da competitividade de projetos e produtos. FABAVI em Revista, Vitória, v. 1, n. 1. 2002. Disponível em: < http://www.fabavi.br/revista/ index.php>. Acesso em: 23 abr.2004.

FIGUEIREDO, Saulo Porfírio. Compartilhamento do conhecimento. Disponível em: <http://www.kmol.online.pt/artigos>. Acesso em: 29 set. 2004.

FRANCHINELLI, Ana Cristina; MARCON, Christian; MOINET, Nicolas. A prática da gestão de redes: uma necessidade estratégica da sociedade da informação. Disponível em: <http://www.comciencia.br/ reportagens/socinfo/info14.htm>. Acesso em: 11 out. 2004.

FLEURY, Afonso; FLEURY, Maria Tereza Leme. Aprendizagem e inovação organizacional: as experiências de Japão, Coréia e Brasil. São Paulo: Atlas, 1995. 237 p.

GARVIN, A. David. Building a learning organization. Harvard Business Review, Boston, v. 71, n. 4, p. 78-91, Jul./Aug. 1993.

KROGH, Georg von; ICHIJO, Kazuo; NONAKA, Ikujiro. Facilitando a criação de conhecimento: reinventando a empresa com o poder de inovação contínua. Rio de janeiro: Campus, 2001.

LASTRES, Helena Maria Martins; FERRAZ, João Carlos. Economia da informação, do conhecimento e do aprendizado. In: LASTRES, Helena M. M.; ALBAGLI, Sarita (Org.). Informação e globalização na era do conhecimento. Rio de Janeiro: Campus, 1999. cap. 1, p. 27-57.

LEMOS, Cristina. Inovação na era do conhecimento. In: LASTRES, Helena M. M.; ALBAGLI, Sarita (Org.). Informação e globalização na era do conhecimento. Rio de Janeiro: Campus, 1999. cap. 5, p. 122-144.

LESCA, H.; AlMEIDA, F. C. Administração estratégica da informação. Revista de Administração, São Paulo, v. 29, n. 3, p. 66-75, jul./set. 1994.

MACEDO, Tonia Marta Barbosa. Redes informais nas organizações: a co-gestão do conhecimento. Ciência da Informação, Brasília, v. 28, n. 1, p. 94-100, jan. 1999.

MANUAL de Oslo: proposta de diretrizes para coleta e interpretação de dados sobre inovação tecnológica. Tradução da Financiadora de Estudos e Projetos. Paris: OCED, 2004. Disponível em: <http:// www.fcfrp.usp.br/HP-download/manual_de_oslo.pdf $>$. Acesso em: 18 nov. 2004.

MARTELETO, Regina Maria. Análise de redes sociais: aplicação nos estudos de transferência da informação. Ciência da Informação, Brasília, v. 30, n. 1, p. 71-81, jan./abr. 2001.

Redes e configurações de comunicação e informação: construindo um modelo interpretativo de análise para o estudo da questão do conhecimento na sociedade. Investigación Bibliotecológica, México, v. 14, n. 29, p. 69-94, jul./dic. 2000. 


\section{Maria Inês Tomaél / Adriana Rosecler Alcará / Ivone Guerreiro Di Chiara}

MCGARRY, Kevin. O contexto dinâmico da informação: uma análise introdutória. Brasília: Briquet de Lemos, 1999.

MIRANDA, Roberto Campos da Rocha. O uso da informação na formulação de ações estratégicas pelas empresas. Ciência da Informação, Brasília, v. 28, n. 3, p. 286-292, set./dez. 1999.

MOLINA, José Luiz. La ciencia de las redes. Apuntes de Ciência y Tecnologia, Barcelona, n. 11, p. 36-42, jun. 2004. Disponível em: < http:/ /seneca.uab.es/antropologia/jlm/public_archivos/ciencia.pdf $>$. Acesso em: 23 nov. 2004.

NONAKA, Ikujiro; TAKEUCHI, Hirotaka. Criação de conhecimento na empresa: como as empresas japonesas geram a dinâmica da inovação. 9. ed. Rio de Janeiro: Campus, 1997.

SAÉNZ, Tirso W.; GARCÍA CAPOTE, Emílio. Ciência, inovação e gestão tecnológica. Brasília: CNI/IEL/SENAI/ABIPTI, 2002. 136p.

SCHLEMM, Marcos Mueller; SOUZA, Queila Regina. COEP Paraná e empreendedorismo social: uma experiência de gestão do conhecimento para inovação. Disponível em: <http://www.coepbrasil.org.br/ downloads/tese_queila.doc>. Acesso em: 09 set. 2004.

SENGE, Peter. A quinta disciplina: arte, teoria e prática da organização de aprendizagem. 10. ed. São Paulo: Best Seller, 1995. 351p.

A quinta disciplina: caderno de campo: estratégias e ferramentas para construir uma organização que aprende. Rio de Janeiro: Qualitymark, 1995. 592p.
SHORE, Barry; VENKATACHALAN, A. R. Evaluating the information sharing capacities of supply chain partners. Disponivel em: <http:// www.emeraldinsight.com/researchregister >. Acesso em: 10 ago. 2004.

SODRÉ, Muniz. Antropológica do espelho: uma teoria da comunicação linear e em rede. Petrópolis: Vozes, 2002.

TÁLAMO, Maria de Fátima G. M. A Pesquisa: recepção da informação e produção do conhecimento. DataGramaZero: revista de ciência da informação, Rio de Janeiro, v. 5, n. 2, abr.2004. Disponível em: < http:/ /www.dgzero.org>. Acesso em: 17 nov. 2004

TONET, Helena. Validação de uma escala de atitudes frente ao compartilhamento de conhecimento no trabalho. Disponível em: < http:/ /www.kmol.online.pt/artigos>. Acesso em: 29 set. 2004.

VAN AKEN, Joan E.; WEGGEMAN, Mathieu P. Managing learning in informal innovation networks: overcoming the Dapne-dilemma. RED Management, Oxford, v. 30, n. 2, p. 139-149, 2000.

WELLMAN, Barry. Are personal communities local? a dumptarian reconsideration. Social Networks, Amsterdam, v. 18, p. 347-354, 1996.

YU, Zhenxin; YAN, Hong; CHENG, T. C. E. Benefits of information sharing with supply chain partnerships. Industrial Management $\mathcal{E}$ Data Systems, v. 101, n. 3, p. 114-121, 2001. 